\section{Estudo \\ Ecidebate}

em Testão

Plamejamento
Revista Estudo \& Debate, Lajeado, v. 25, n. 2, 2018. ISSN 1983-036X

DOI: http://dx.doi.org/10.22410/issn.1983-036X.v25i2a2018.1749

\title{
GREEN BRAND: A PERCEPÇÁO DOS JOVENS CONSUMIDORES SOBRE AS MARCAS VERDES
}

\author{
Larissa Tayla Alfenas ${ }^{1}$, Luiz Rodrigo Cunha Moura ${ }^{2}$, Nina Rosa da Silveira Cunha
}

\begin{abstract}
Resumo: A preocupaçáo acerca dos problemas ambientais vem crescendo ao longo do tempo, bem como a percepçáo dos consumidores de que a degradaçáo da natureza também vem aumentando ao longo do tempo. Essa percepção pode modificar o processo decisório dos consumidores em relação à aquisiçáo de produtos e serviços. O objetivo desse trabalho é o de mensurar a percepção dos jovens consumidores à respeito das marcas verdes ou green brand. Assim, foi realizada uma pesquisa descritiva com 700 alunos de um Centro Universitário localizado em uma metrópole brasileira. Os conceitos relativos às marcas verdes mensurados foram: afeto, preocupação ambiental, preferência, imagem da marca, confiança na marca, satisfaçáo, força da marca, qualidade percebida, lealdade, valor percebido, comunicação boca-a-boca, risco percebido e propensão a pagar mais caro. Os resultados obtidos indicam que os jovens consumidores ainda não valorizam as marcas verdes. Apesar do risco percebido e do afeto terem apresentado bons resultados, a percepçáo do consumidor sobre os produtos, serviços e marcas verdes em termos de crenças, confiança, qualidade e intençóes comportamentais ainda apresentaram valores baixos e medianos. Tanto a propensão dos jovens consumidores em pagar um preço premium por marcas verdes foi muito baixa quanto o valor percebido dessas marcas.
\end{abstract}

Palavras-chave: Marketing Verde. Comportamento do Consumidor. Green Brand. Branding.

\section{GREEN BRAND: YOUNG CONSUMER'S PERCEPTION ABOUT GREEN BRANDS}

\begin{abstract}
Concern about environmental problems has grown over time, as well as the consumer's perception that the nature degradation has also increased over time. This perception may change the consumers decisionmaking process in relation to the products purchase and services. The objective of this study is to measure the perception of young consumers regarding green brands or green brand. Thus, a descriptive research was carried out with about 700 students from an University Center located in a Brazil's metropolis. The concepts related to green brands measured were: affection, environmental concern, preference, brand image, confidence in the
\end{abstract}

1 Graduanda em Engenharia de Produção pelo Centro Universitário UNA; Bolsista de Iniciação Científica do Centro Universitário UNA; laratayla@hotmail.com

2 Doutor em Administraçáo pela Universidade Federal de Minas Gerais (UFMG); Professor Adjunto do Centro Universitário UNA; luizrcmoura@gmail.com

3 Doutora em Economia Rural pela Universidade Federal de Viçosa (UFV); Professora Titular da Universidade Federal de Viçosa (UFV); ninarosa@ufv.br 
brand, satisfaction, brand strength, perceived quality, loyalty, perceived value, word of mouth communication, perceived risk and propensity to pay more. The results indicate that young consumers still do not value green brands. Although perceived risk and affect have shown good results, consumer perceptions of green products, services and brands in terms of beliefs, confidence, quality and behavioral intentions have still presented low and medium values. Both the propensity of young consumers to pay a premium price for green brands was very low as the perceived value of these brands.

Keywords: Green marketing. Consumer Behavior. Green Brand. Branding.

\section{INTRODUÇÃO}

Ao longo dos anos, desde a antiguidade, as atividades realizadas pelos seres humanos sempre causaram impacto no meio ambiente, sempre que esse processo se acelerou a partir da revolução industrial, a qual aumentou de sobremaneira a escala de produção e também de poluição e degradação do meio ambiente (DIETERICH, 2014).

A partir do estabelecimento de normas que visavam proteger a natureza, originou-se o conceito de desenvolvimento sustentável, que procura satisfazer as necessidades atuais da população, de modo que não comprometa as geraçōes futuras de usufruírem também dos recursos naturais (OTTMAN, 1994; TRUJILLO; ARROYO; CARRETE, 2014).

Devido à preocupação da sociedade, as organizaçóes têm dado maior atenção à responsabilidade ambiental e têm adotado o conceito de marketing verde, conquistando assim maiores oportunidades no mercado. Como consequência da preocupação ambiental por partes dos consumidores, as vendas de produtos verdes têm aumentado de forma significativa, de forma a atender a crescente demanda do mercado (CHEN et al., 2006; DIETERICH, 2014).

A grande maioria das organizaçóes respondeu positivamente ao desenvolvimento das novas preferências dos consumidores por adquirirem produtos que sejam sustentáveis do ponto de vista ambiental. Porém, essas organizaçóes ainda têm o desafio mostrar ao consumidor que estes produtos apresentam um bom desempenho funcional quando comparados aos demais produtos convencionais disponíveis no mercado (NG et al., 2013). Os consumidores querem adquirir produtos que sejam menos agressivos ao meio ambiente, e que estejam conforme as normas de proteçáo ambiental e desenvolvimento sustentável (CHANG; CHEN, 2014).

Assim, esse trabalho tem por objetivo identificar o nível de percepçâo dos consumidores sobre a importância de adquirir produtos de marcas "verdes" e quais são os fatores que os influenciam a realizar compras.

Em termos teóricos, esse trabalho se justifica em virtude de que nas últimas três décadas o marketing verde tem sido um assunto recorrente em pesquisas acadêmicas. As organizaçóes, com o intuito de atender às satisfaçóes de seus clientes, têm investido no desenvolvimento de seu mix de produtos, e esse novo comportamento dos consumidores está criando uma nova economia global, baseada no consumo de produtos sustentáveis (CHEN, 2011).

Estudos recentes sobre o marketing verde e o comportamento do consumidor abordam diversas facetas entre essa relação. No caso de Fallah e Ebrahimi (2014) e Kaur (2014) 
descobriu-se que práticas de marketing verde afetam a intenção de compra dos consumidores. Além disso, Trujillo; Arroyo e Carrete (2014) também estudaram as práticas do marketing verde, baseadas no mix de marketing (4p's de marketing) no México. Na Malásia, Rasidah, Jamal e Sumarjan (2014) estudaram as intençóes comportamentais (lealdade, propaganda boca-a-boca e afins) dos turistas em relação às práticas de sustentabilidade e de marketing verde dos hotéis daquele país. A percepção dos consumidores em relação ao marketing verde dos fabricantes de carros elétricos na Alemanha foi estudada por Dieterich (2014).

Ainda em termos teóricos, o estudo das percepçôes dos consumidores sobre o seu nível de preocupação com os assuntos ambientais, sua consciência ambiental e a sua preferência de compra de marcas verdes ajudam a preencher a lacuna dos novos consumidores que estấo formando os mercados.

Por fim, há de se considerar ainda que os fatores que influenciam a realizaçáo de compras de produtos verdes variam entre os países, sendo que a cultura é um fator importante que influencia o comportamento dos consumidores (KAUR, 2014; TRUJILLO; ARROYO; CARRETE, 2014). Assim, é importante o estudo sobre a percepção dos consumidores no Brasil, considerando a sua cultura.

Em termos gerenciais, esse trabalho se justifica por causa da mudança de comportamento dos consumidores, as empresas estão se empenhando para satisfazer as necessidades dos mesmos e, para isso, se faz necessário conhecer e avaliar quais são as variáveis que influenciam em suas decisóes de compra e a importância do marketing verde é cada vez maior (CHANG; CHEN, 2014; POLONSKY, 1994) e pode ser verificada ao afirmar que organizaçóes de todos os tipos estão lançando campanhas verdes. Isto se deve ao fato de que os consumidores em geral desejam consumir com consciência em prol do meio ambiente (CASTRO et al., 2016; BONINI; OPPENHEIM, 2009).

Portanto, a realização desse estudo constitui uma importante fonte de pesquisa para as organizações que visam adotar práticas do marketing verde, cujo objetivo seja o atendimento às necessidades atuais dos consumidores. Conhecer as preferencias dos potenciais clientes e satisfazê-las constitui uma estratégia de mercado capaz de garantir a continuidade das atividades organizacionais e reposicioná-las no mercado cada vez mais competitivo.

\section{REFERENCIAL TEÓRICO}

Nessa etapa são descritos os principais conceitos sobre o marketing verde e sobre os construtos usados nessa pesquisa: afeto, preocupação ambiental, preferência, imagem da marca, confiança na marca, satisfação, força da marca, qualidade percebida, lealdade, valor percebido, comunicação boca-a-boca, risco percebido e propensão a pagar mais caro.

\subsection{O Marketing Verde e Seus Componentes}

Como consequência da mudança de comportamento dos consumidores, as empresas estáo se empenhando para satisfazer as necessidades de seus consumidores, e o marketing verde é o pilar desse processo. Nos últimos anos, o marketing verde é uma das noções emergentes no campo de marketing, e seu conceito tem sido aceito e aplicado na prática. Pode ser aplicado para facilitar a estratégia de diferenciação das empresas, e destina-se a 
satisfazer os desejos dos clientes, na esfera ambiental. $\mathrm{O}$ marketing verde é um conceito amplo, formado por todas as atividades de marketing que visam desenvolver e estimular o comportamento dos consumidores de produtos sustentáveis. As empresas devem realizar estudos sobre o comportamento de seus clientes, com o intuito de detectar as suas necessidades e, a partir disso, elaborar estratégias de marketing que sejam eficazes (CHANG; CHEN, 2014; CHEN, 2010).

Diversos estudos visaram estudar o comportamento do consumidor em relação às marcas verdes. Há um estudo sobre a percepção dos consumidores sobre o green brand no Egito (MOURAD; AHMED, 2012), foi realizado uma pesquisa para identificar as intençóes dos consumidores em comprar produtos e serviços de marcas verdes ou ter preferência sobre esses produtos (RIZWAN et al., 2014; IRFAN et al. 2014; ABKAR et al., 2014), também estudos sobre a relação entre os componentes da marca verde, como satisfação, afeto, confiança e suas consequências sobre a lealdade (KANG; HUR, 2012), ou ainda sobre a força da marca verde baseada na qualidade, risco e consciência das marcas verdes (CHANG; CHEN, 2014), ou baseada também na qualidade, imagem e valor da marca (NG et al., 2014). Os construtos usados nesse trabalho são baseados nessas pesquisas e são descritos a seguir.

Consciência significa ter informação sobre alguma coisa. Quando as pessoas avaliam um determinado produto - suas características e benefícios -, eles estão adquirindo consciência verde. Quanto maiores informaçôes o cliente tem a respeito de um produto, maiores são as chances de compra, e quanto maiores são os níveis de estudo do cliente, maiores são as intenções de adquirir um produto sustentável. O contrário também é válido, quanto menos conhecimento a respeito dos benefícios que os produtos verdes oferecem, menores são as chances dos consumidores adquiri-los (RIZWAN et al., 2014).

As pessoas desejam ser mais conscientes das vantagens que os produtos verdes podem oferecer. Uma publicidade voltada para esclarecer as vantagens que os produtos oferecem constituiu numa estratégia de divulgação do produto, com o intuito de inseri-lo na lista de consumo dos clientes (RIZWAN et al., 2014). A consciência de marca é medida por questôes relacionadas ao conhecimento, à lembrança e às fontes de informação sobre as marcas verdes, conforme os estudos de Mourad e Ahmed (2012) e Chang e Chen (2014).

A confiança é a esperança que a outra parte irá cumprir e agir conforme acordado. Há três principais causas de confiança: crença na honestidade, boa vontade e aptidão. A confiança pode ser traduzida como a probabilidade de um consumidor comprar um determinado produto tendo consciência ambiental (RIZWAN et al., 2014).

A credibilidade da marca se atém à confiança que os consumidores têm nas organizaçóes para que estas satisfaçam suas exigências quanto à oferta de produtos/serviços (NG et al., 2013). Assim, a confiança na marca é medida por meio de questóes que medem a percepção de credibilidade em termos de compromissos com as questóes ambientais e do desempenho dos produtos e serviços em relação ao meio ambiente, considerando as pesquisas de Ng et al. (2014), Kang e Hur (2012), Rizwan et al. (2014) e Martínez (2015).

O valor verde percebido é a avaliação de um cliente sobre o benefício global que um produto verde pode oferecer (RIZWAN et al., 2014) ou ainda é a intenção do cliente de 
comprar novamente o produto numa próxima oportunidade, pois seus benefícios superaram as expectativas do consumidor (NG et al., 2013).

As preocupaçóes dos consumidores quando vão comprar um determinado produto, são as diferentes vantagens que cada empresa concorrente oferece. Um produto verde oferece o mesmo lucro que um produto não verde, porém ele aumenta o valor percebido na mente dos clientes e maiores são as chances de comprá-los. Estudos indicam que há uma boa relação entre o valor verde percebido e a intenção de compra verde (NG et al., 2013).

O valor verde percebido é mensurado por meio de questóes que abordam os benefícios ao meio ambiente, além da sua relação custo-benefício, conforme presente nos manuscritos de $\mathrm{Ng}$ et al. (2014) e Rizwan et al. (2014).

A imagem da marca verde pode ser definida como o conjunto de percepçóes na mente do consumidor, e que está ligada a compromissos e preocupaçóes ambientais pela organização (RIZWAN et al., 2014). Ela se refere às avaliaçóes e percepçóes que estáo presentes na memória dos consumidores ao se lembrarem de uma marca específica e que também está relacionada à preocupação ambientar e sustentabilidade (CHEN, 2010).

Uma imagem positiva da marca é criada na mente dos consumidores, a partir do instante em que ela provoca emoçóes, atitudes e comportamentos nesses consumidores (NG et al., 2013). A imagem da pode ser medida por intermédio de questóes que abordam a percepção dos consumidores em termos da reputação, nível de reciclagem e vantagens das marcas verdes em comparação com as marcas tradicionais. Esses itens foram considerados nas pesquisas de Doshanov e Ahmad (2015), Irfan et al. (2014) e Mourad e Ahmed (2012).

O risco percebido é definido como um arranjo de impressão e resultado negativo criado mentalmente pelos consumidores, e afeta a decisão de compra dos mesmos. Se as pessoas acham que não terão suas necessidades atendidas ou que terão problemas após a compra, elas evitam adquirir esses produtos, e essa situação constitui o risco verde percebido pelos consumidores (RIZWAN et al., 2014).

O risco percebido pode ser baseado em duas situaçóes: más práticas resultando em engano ao consumidor e propaganda negativa boca a boca. $\mathrm{O}$ risco percebido também se refere à percepção que o cliente tem do produto ser de má qualidade e não satisfazer suas expectativas. Investir na redução do risco percebido significa obter a confiança do cliente e aumento de vendas de produtos verdes (GREGG; WALCZAK, 2008; RIZWAN et al., 2014).

Então, pode-se concluir que há uma relação negativa entre o risco verde percebido e a intenção de compra do consumidor. Se há um alto risco percebido, o cliente não compra o produto; se o risco percebido é baixo, o produto é vendido (RIZWAN et al., 2014).

$\mathrm{O}$ risco percebido é mensurado através de questôes relativas à possibilidade e à chance dos produtos verdes prejudicarem o meio ambiente, de não apresentaram o desempenho "ambiental" que prometem e dos possíveis problemas advindos do seu uso pelos consumidores, conforme descrito nos trabalhos de Chang e Chen (2014) e Rizwan et al. (2014). 
A qualidade percebida se refere à avaliação que os clientes têm a respeito do funcionamento do produto com relação aos objetivos pretendidos ao adquiri-los. Ela é considerada um dos fatores que mais influenciam o consumidor no ato da compra (NG et al., 2013), podendo ser medida pela percepção da satisfação e do atendimento às expectativas dos clientes e se os produtos e serviços são de alta qualidade, de acordo com os artigos de Chang e Chen (2014), Ng et al. (2014) e Doshanov e Ahmad (2015).

A força da marca de uma companhia é descrita como o barômetro, com o intuito de determinar o grau de valor adicionado àquela determinada marca, devido a seus produtos e serviços oferecidos no mercado (FARQUAR, 1989). Ela é formada tanto por ativos quanto pelos passivos, os quais estáo associados aos elementos da marca (nome, logotipo, personagem, etc.) que geram valores únicos ou diferenciais para os clientes (AAKER, 1996). Ela pode ser medida por questóes que abordam as percepçóes do consumidor em termos de que vale a pena e de que é uma decisão inteligente comprar as marcas verdes, mesmo que elas sejam mais caras, que haja outras marcas no ponto de venda e que as outras marcas sejam similares nos aspectos não ambientais do produto. Essas questóes estão presentes nos artigos de Kang e Hur (2012), Chang e Chen (2014) e Ng et al. (2014).

A intenção de compra verde é definida como o desejo que os consumidores têm em comprar produtos que não sejam nocivos ao meio ambiente. A intenção de aquisiçáo de tais produtos deu-se em consequência da evolução da tecnologia, que trouxe efeitos negativos ao planeta, como a poluição do ar, da água, destruição da camada de ozônio, etc. (RIZWAN et al., 2014). Ela é medida pela disposição, pretensão, vontade e propensão dos consumidores em adquirir produtos e serviços de marcas verdes, conforme descrito em Doshanov e Ahmad (2015) e Rizwan et al. (2014).

O desejo de pagar um preço mais alto por uma marca verde pode ser descrito como a quantidade de recursos financeiros que o consumidor está disposto a pagar a mais por uma marca verde em comparação com produtos e serviços de marcas comuns (KONUK; RAHMAN; SALO, 2015). Quando os consumidores são preocupados com a degradação do meio em que vivem, eles optam por pagar um preço maior por produtos que náo contribuem para a degradação do meio ambiente (PEATTIE, 1999) e compram aqueles produtos que náo agridem o meio ambiente (CHEN, 2010; IRFAN et al., 2014). Muitos clientes estão dispostos a pagar um maior preço pelos produtos verdes, desde que eles não sejam agressivos à natureza. As empresas devem investir na promoção de seus produtos verdes e fazer com que os mesmos sejam inseridos no dia a dia dos consumidores (RIZWAN et al., 2014). O desejo de pagar um preço mais alto pode ser medido por meio de itens que meçam essa disposição em função do desempenho ambiental e das características ambientais dos produtos, conforme descrevem Konuk, Rahman e Salo (2015).

$\mathrm{O}$ afeto em relação à marca pode ser definido como a capacidade da marca em gerar reaçóes positivas nos consumidores em relação ou durante o uso do produto ou serviço. São as sensaçóes percebidas e sentidas pelo consumidor e que são relacionadas à marca. $\mathrm{O}$ mesmo ocorre em relação ao afeto relacionado às marcas verdes, o qual pode ser medido por meio de questôes que abordem sentimentos tais como fecilicidade, prazer e sensação de bem-estar por comprar produtos verdes conforme descrito em Kang e Hur (2012). 
A satisfação pode ser definida como o nível de prazer ou a sensação de encantamento por parte do consumidor após o consumo do produto ou serviço. Ele é descrito como o nível de contentamento e a capacidade da marca em atender às expectativas, necessidade e desejos ecológicos por parte dos consumidores, além das preocupaçóes ambientais ou ecológicas dos consumidores (MOURAD; AHMED, 2012; KANG; HUR, 2012; CHEN, 2010). Ela é mensurada por meio de perguntas relacionadas à felicidade, satisfação, alegria, entre outros aspectos relacionados à utilizaçáo e aquisição de marcas verdes por parte dos consumidores, de acordo com o descrito nas pesquisas de Mourad e Ahmed (2012), Martínez (2015) e Kang e Hur (2012).

Em relaçáo à lealdade, ela pode ser entendida como a intençáo e o comprometimento dos consumidores em recomprar uma determinada marca ao longo do tempo. Assim, ela é a aquisiçấo recorrente de marcas verdes por parte do consumidor. A lealdade assume diferentes contextos, podendo ser expressa pela lealdade a uma loja "verde", lealdade a um serviço de marca verde, a um produto ecologicamente amigável e afins (KANG; HUR, 2012). Ela pode ser medida por meio de perguntas relacionadas ao uso futuro, à compra e às opçóes dos consumidores no futuro em relação a produtos e serviços de marcas verdes, de acordo com os trabalhos de Kang e Hur (2012) e Martínez (2015).

A propaganda boca-a-boca sobre marcas verdes pode ser definida como o nível de intençáo ou desejo do consumidor em comunicar - conversar, postar, escrever, etc. - para outras pessoas sobre as suas marcas verdes de preferência (KONUK; RAHMAN; SALO, 2015). Assim, esse construto pode ser medido por meio de questóes que abordem esse tipo de comportamento por parte do consumidor conforme pesquisa de Konuk, Rahman e Salo (2015).

\section{METODOLOGIA}

Essa é uma pesquisa descritiva de abordagem quantitativa na qual foi utilizada estatística descritiva.

Os construtos selecionados foram baseados em estudos em o tema green brand foi o tema estudado. Esse estudos são de Doszhanov e Ahmad (2015), Jang, Kim e Lee (2015), Konuk, Rahman e Salo, (2015), Martinez (2015), Chang e Chen (2014), Irfan et al. (2014), Ng et al. (2014), Rizwan et al. (2014) e Mourad e Ahmed (2012). Assim, por exemplo, nesse último trabalho de Mourad e Ahmed (2012) o objetivo foi o de identificar a percepção de green brand pelos consumidores no Egito, por meio de escalas que mensuravam os construtos confiança na marca verde, consciência da marca verde, satisfaçáo com marcas verdes, imagem de marcas verdes e preferência por marcas verdes. No caso do estudo de Rizwan et al. (2014), foram estudadas as intençôes dos consumidores em adquirir marcas verdes. Foram usadas escalas para avaliar a confiança na marca verde, a força (brand equity) da marca verde, a intenção de compra de marcas verdes, risco percebido de marcas verdes, além da imagem e consciência das marcas verdes. Isso foi feito em todos os estudos citados nesse parágrafo. Além disso, esses estudos também serviram de apoio para a elaboração do instrumento de coleta de dados - o questionário - por meio da adaptaçáo das escalas usadas nessas pesquisas. Assim, foram utilizadas todas as opçóes de escalas de cada um dos artigos utilizados como referência pare a construção do questionário. A tradução contou 
com a participação de dois professores doutores da área de conhecimento de marketing para validar o conteúdo traduzido de cada uma das questóes.

Para a realização da pesquisa foi usado o questionário estruturado, composto por 57 perguntas, todas fechadas, com um escalonamento variando entre zero e dez pontos e âncoras com as afirmativas "discordo totalmente" e "concordo totalmente". A escala usada pode ser classificada como intervalar com 11 opçóes de marcação, entre "0" e "10", onde " 0 " estava relacionado com "discordo totalmente" e "10" estava relacionado com "concordo totalmente". Essas 57 perguntas formam os construtos (afeto, preocupação ambiental, preferência, imagem da marca, confiança na marca, satisfação, força da marca, qualidade percebida, lealdade, valor percebido, comunicaçáo boca-a-boca, risco percebido e propensão a pagar mais caro) que indicam a percepção dos jovens consumidores em relação às marcas verdes. Esses construtos formaram o questionário e cujos itens são exibidos na análise de dados.

O universo da pesquisa foi formado por alunos de uma IES localizada no sudeste do Brasil e os dados foram coletados em seus campi localizados em duas cidades próximas entre si. Assim, esse processo gerou uma amostra classificada como uma amostra por conveniência. Esse tipo de amostra é uma seleção de pessoas específicas para a aplicação dos questionários e são mais fáceis e rápidas de serem abordadas (MALHOTRA, 2011). O público de jovens estudantes foi escolhido em virtude de que eles são o alvo de muitos segmentos de mercado (roupas, celulares, bebidas alcoólicas, lazer, entre outros) e as questôes ambientais estão cada vez mais presente no dia-a-dia da sociedade e os jovens consumidores são um segmento muito valorizado pelas empresas principalmente em virtude de uma possibilidade de fidelidade a longo prazo.

A coleta de dados ocorreu de forma presencial nos diversos campi dessa IES e esse processo ocorreu antes das aulas e durante os intervalos no período da noite. O processo de amostragem foi por conveniência, ou seja, a amostra foi composta pelas pessoas que aceitaram participar da pesquisa, não havendo a aplicação de nenhuma técnica de aleatoriedade para a escolha dos respondentes.

No questionário havia duas perguntas idênticas. Caso o respondente marcasse essas duas questóes com uma diferença maior de dois pontos para mais ou para menos, esse questionário passaria a ser inválido. Essa foi uma forma de verificar o nível de atençấo e de comprometimento dos respondentes ao preencher o questionário. Foram aplicados 700 questionários, dos quais 248 foram considerados inválidos, 25 estavam em branco e 427 foram considerados válidos. Os dados foram tabulados em uma planilha Excel e a análise de dados ocorreu por meio da estatística descritiva.

\section{RESULTADOS E ANÁLISES}

Para a análise dos construtos, foi usada a média e o desvio padrão dos itens que formam as questóes que compóem cada construto. 
Tabela 1 - Percepção de consciência da marca

\begin{tabular}{l|c|c}
\hline \multicolumn{1}{c|}{ Questáo } & Média & $\begin{array}{c}\text { Desvio } \\
\text { Padráo }\end{array}$ \\
\hline $\begin{array}{l}\text { Eu tenho conhecimento dos esforços ambientais feitos pelos produtos e } \\
\text { serviços com marcas "verdes" }\end{array}$ & 5,5 & 2,9 \\
\hline $\begin{array}{l}\text { Jornais e revistas também são uma fonte de conhecimento sobre as } \\
\text { marcas verdes. }\end{array}$ & 5,1 & 3,1 \\
\hline $\begin{array}{l}\text { Você já viu alguns rótulos e slogans contidos em embalagens de } \\
\text { produtos com marcas "verdes". }\end{array}$ & 5,8 & 3,1 \\
\hline $\begin{array}{l}\text { Você pode lembrar-se alguns dos símbolos ambientais que as marcas } \\
\text { "verdes" usam em suas campanhas de marketing. }\end{array}$ & 5,6 & 2,9 \\
\hline $\begin{array}{l}\text { Você pode reconhecer marcas “verdes" entre outras marcas concorrentes } \\
\text { convencionais por causa de seus compromissos ambientais. }\end{array}$ & 5,7 & 2,9 \\
\hline MÉDIA GERAL & 5,5 & \\
\hline
\end{tabular}

Fonte: dados da pesquisa.

Em relação à consciência de marca se percebe que as médias foram muito parecidas entre si e os seus valores não foram altos (Tabela 1). Em relação ao desvio padrão os valores são altos, indicando que existe uma divergência entre os respondentes, com muitos respondentes atribuindo tanto altos valores quanto baixos valores para a consciência de marca.

Assim, é possível concluir que a consciência de marcas verdes junto aos jovens consumidores não é muito alta. Todos os itens variaram entre 5,5 e 5,8, exceto a média para a questão 2, que obteve um valor cerca de $10 \%$ mais baixo. Nesse caso, a causa pode ser que a amostra dessa pesquisa foi formada por jovens e as suas fontes de informação não são mais jornais e revistas, e sim a internet e as mídias sociais.

Mensurar a consciência da marca é importante, pois, esse construto influencia positivamente a preferência por marcas verdes (MOURAD; AHMED, 2012; IRFAN et al., 2014), influencia positivamente a força das marcas verdes (CHANG; CHEN, 2014) e a intenção de comprar marcas verdes (RIZWAN et al., 2014). 
Tabela 2 - Percepção da imagem da marca

\begin{tabular}{l|c|c}
\hline \multicolumn{1}{c|}{ Questáo } & Média & $\begin{array}{c}\text { Desvio } \\
\text { Padrão }\end{array}$ \\
\hline As embalagens de produtos de marcas “verdes” são recicláveis. & 6,8 & 2,8 \\
\hline Os produtos de marcas “verdes” em geral têm uma boa reputação. & 6,2 & 2,6 \\
\hline $\begin{array}{l}\text { Eu acho que produtos de marcas “verdes” são melhores do que os } \\
\text { produtos convencionais. }\end{array}$ & 5,2 & 3,0 \\
\hline $\begin{array}{l}\text { Eu acho que produtos de marcas “verdes” são referências em relação aos } \\
\text { produtos voltados para o meio ambiente. }\end{array}$ & 6,7 & 2,6 \\
\hline MÉDIA GERAL & 6,2 & \\
\hline
\end{tabular}

Fonte: dados da pesquisa.

De acordo com a Tabela 2, em relação à imagem da marca, percebe-se que há uma variação de valores entre as médias, mas os valores não são altos. Logo, é possível concluir que a imagem da marca verde junto aos jovens consumidores não é muito alta. No caso do desvio padrão os valores são altos, indicando que existe uma divergência entre os respondentes, com muitos respondentes atribuindo tanto altos valores quanto baixos valores para a imagem de marca. A maior divergência foi para a questão relativa aos produtos verdes serem melhores do que os produtos comuns.

Os resultados indicam que os respondentes acreditam muito pouco que os produtos e serviços advindos de marcas verdes são melhores do que os produtos oriundos de marcas comuns. Por outro lado, uma parcela maior acredita que as embalagens das marcas verdes são recicláveis e podem ser referência como produtos voltados ao meio ambiente. Mas, mesmo assim, as médias para estas questóes não alcançaram os sete pontos.

No caso da imagem da marca, a sua mensuração é importante, pois, ela influencia positivamente a preferência por marcas verdes (MOURAD; AHMED, 2012; IRFAN et al., 2014), influencia positivamente a satisfação e a confiança nas marcas verdes (CHEN, 2010) e a força da marca (NG et al., 2013). 


\begin{tabular}{l|c|c}
\hline \multicolumn{1}{c|}{ Questáo } & Média & $\begin{array}{c}\text { Desvio } \\
\text { Padráo }\end{array}$ \\
\hline Eu confio nos compromissos ambientais dos produtos de marcas “verdes" & 5,8 & 2,5 \\
\hline $\begin{array}{l}\text { Eu acho que o desempenho ambiental dos produtos de marcas “verdes” é } \\
\text { geralmente confiável. }\end{array}$ & 6,1 & 2,4 \\
\hline $\begin{array}{l}\text { Eu sinto que o argumento ambiental das marcas “verdes” é geralmente } \\
\text { confiável }\end{array}$ & 5,9 & 2,4 \\
\hline $\begin{array}{l}\text { Os produtos de marcas “verdes" mantém as promessas e compromissos } \\
\text { pela proteçáo ambiental. }\end{array}$ & 6,1 & 2,4 \\
\hline MÉDIA GERAL & 6,0 & \\
\hline
\end{tabular}

Fonte: dados da pesquisa.

Em relação à confiança na marca, os resultados indicam que a percepção dos jovens consumidores não muda muito de questão para questão (Tabela 3). A média geral é de apenas seis pontos, indicando que respondentes não confiam muito nas marcas verdes em relação ao meio ambiente. Os valores do desvio padrão indicam que existe uma divergência menor do que os itens anteriores, mas ainda com valores consideráveis.

Em relação à confiança na marca, ela influencia positivamente a preferência pelas marcas verdes (MOURAD; AHMED, 2012), influencia positivamente a força da marca (CHEN, 2010), influencia positivamente a lealdade à marca (KANG; HUR, 2012; MARTÍNEZ, 2015), a satisfação dos consumidores (MARTÍNEZ, 2015) e a intenção em comprar marcas verdes (RIZWAN et al., 2014).

Tabela 4 - Percepção da qualidade percebida

\begin{tabular}{l|c|c}
\hline \multicolumn{1}{c|}{ Questáo } & Média & $\begin{array}{c}\text { Desvio } \\
\text { Padráo }\end{array}$ \\
\hline $\begin{array}{l}\text { O desempenho em relação ao meio ambiente das marcas verdes satisfaz as } \\
\text { minhas expectativas. }\end{array}$ & 5,6 & 2,2 \\
\hline $\begin{array}{l}\text { A qualidade dos produtos de marcas “verdes” é confiável no que diz } \\
\text { respeito à consideração do meio ambiente. }\end{array}$ & 6,0 & 2,4 \\
\hline $\begin{array}{l}\text { O desempenho ambiental das marcas “verdes” atende às minhas } \\
\text { expectativas. }\end{array}$ & 5,8 & 2,3 \\
\hline $\begin{array}{l}\text { A qualidade dos produtos das marcas "verdes” considerando as questóes } \\
\text { ambientais é muito alta. }\end{array}$ & 5,5 & 2,3 \\
\hline MÉDIA GERAL & 5,7 & \\
\hline
\end{tabular}

Fonte: dados da pesquisa.

O resultado obtido para a qualidade percebida das marcas verdes é bastante similar à consciência de marca e à confiança na marca (Tabela 4). A variação entre as questóes 
foi pequena e a média geral foi baixa não alcançando os seis pontos. Assim, os jovens consumidores náo percebem uma grande qualidade em relaçáo aos produtos de marcas verdes. O desvio padrão apresentou valores moderados, indicando um consenso maior dos respondentes sobre a qualidade percebida de marcas verdes.

É importante mensurar a qualidade percebida, pois, ela afeta positivamente a percepçáo de risco e a força da marca (CHANG; CHEN, 2014) e o valor percebido, credibilidade da marca e a imagem da marca (NG et al., 2014).

Tabela 5 - Percepção de valor percebido

\begin{tabular}{l|c|c}
\hline \multicolumn{1}{c|}{ Questáo } & Média & $\begin{array}{c}\text { Desvio } \\
\text { Padráo }\end{array}$ \\
\hline $\begin{array}{l}\text { Eu compro marcas “verdes” por causa dos benefícios ao meio ambiente que } \\
\text { ela oferece em comparaçáo com as marcas convencionais. }\end{array}$ & 5,5 & 2,7 \\
\hline $\begin{array}{l}\text { Os produtos de marcas “verdes” oferecem uma melhor relaçáo custo- } \\
\text { benefício do que produtos de marcas tradicionais. }\end{array}$ & 3,4 & 2,7 \\
\hline $\begin{array}{l}\text { Eu compro marcas “verdes” porque elas se preocupam mais com o meio } \\
\text { ambiente do que as marcas tradicionais. }\end{array}$ & 5,3 & 2,6 \\
\hline $\begin{array}{l}\text { Eu comparo marcas “verdes” porque o benefício ao meio ambiente vale a } \\
\text { pena. }\end{array}$ & 5,5 & 2,7 \\
\hline MÉDIA GLOBAL & 4,9 & \\
\hline
\end{tabular}

Fonte: dados da pesquisa.

Conforme ocorreu com outros construtos, os resultados apresentados na Tabela 5 indicam que o valor percebido das marcas verdes apresentou uma avaliaçáo baixa por parte dos respondentes. Nesse caso, a média geral ficou abaixo dos cinco pontos. A da relação "custo-benefício" das marcas verdes em comparação com as marcas tradicionais apresentou um valor muito baixo. As outras questóes apresentaram uma média um pouco acima de cinco pontos. Esse resultado pode ser explicado por uma percepçáo de qualidade relativamente baixa, como já foi descrito no item anterior em conjunto com uma percepção de preço mais alto em comparação com as marcas tradicionais. Em relação ao desvio padrão, os seus valores também apresentaram valores muito próximos entre si e com valores altos, indicando divergência entre os respondentes.

Em relação ao valor percebido, esse construto afeta positivamente a força da marca (NG et al., 2014), a intenção em comprar produtos e serviços de marcas verdes (RIZWAN et al., 2014) e a intenção em usar produtos verdes (DOSZHANOV; AHMAD, 2015). 


\begin{tabular}{l|c|c}
\hline \multicolumn{1}{c|}{ Questão } & Média & $\begin{array}{c}\text { Desvio } \\
\text { Padráo }\end{array}$ \\
\hline $\begin{array}{l}\text { Eu estou feliz com a decisão de escolher marcas “verdes” por causa de seus } \\
\text { compromissos ambientais. }\end{array}$ & 5,6 & 2,6 \\
\hline $\begin{array}{l}\text { Eu acredito que é a coisa certa utilizar marcas “verdes” por causa de seu } \\
\text { desempenho ambiental. }\end{array}$ & 6,2 & 2,4 \\
\hline $\begin{array}{l}\text { No geral, eu estou contente de ser cliente de marcas “verdes” porque elas } \\
\text { são ambientalmente amigáveis. }\end{array}$ & 5,8 & 2,6 \\
\hline $\begin{array}{l}\text { No geral, eu estou satisfeito com as marcas “verdes” por causa de sua } \\
\text { preocupação ambiental. }\end{array}$ & 6,2 & 2,6 \\
\hline MÉDIA GERAL & 5,9 & \\
\hline
\end{tabular}

Fonte: dados da pesquisa.

A satisfação com as marcas verdes também apresenta resultados coerentes com os outros itens avaliados até o presente momento (Tabela 6). A sua percepção não é alta, apresentando uma avaliação abaixo dos seis pontos e as quatro questóes que medem esse construto apresentam uma avaliaçáo coerente entre si. Da mesma forma que ocorreu com o item anterior, no caso da satisfação com as marcas verdes, os valores do desvio padrão também apresentaram valores muito próximos entre si e com valores altos, indicando divergência entre os respondentes.

No caso da satisfação com as marcas verdes, esse construto deve ser mensurado, pois, ele influencia positivamente a preferência dos consumidores pelas marcas verdes (MOURAD; AHMED, 2012), influencia a força da marca (CHEN, 2010), influencia a confiança na marca verde e o afeto na marca (KANG; HUR, 2012), além da lealdade à marca verde (MARTÍNEZ, 2015).

Tabela 7 - Percepção de preferência

\begin{tabular}{l|c|c}
\hline \multicolumn{1}{c|}{ Questão } & Média & $\begin{array}{c}\text { Desvio } \\
\text { Padrão }\end{array}$ \\
\hline $\begin{array}{l}\text { Faz sentido usar uma marca "verde”, em vez de outras marcas por causa de } \\
\text { seus compromissos ambientais, mesmo se os produtos forem os mesmos. }\end{array}$ & 6,4 & 2,4 \\
\hline Eu prefiro comprar as marcas que são ambientalmente amigáveis. & 6,5 & 2,6 \\
\hline $\begin{array}{l}\text { Eu prefiro comprar produtos das marcas e empresas que têm “certificação } \\
\text { verde" }\end{array}$ & 6,1 & 2,5 \\
\hline $\begin{array}{l}\text { Eu prefiro produtos de marcas “verdes” sobre produtos de marcas } \\
\text { convencionais. }\end{array}$ & 5,9 & 2,4 \\
\hline $\begin{array}{l}\text { Eu prefiro produtos de marcas “verdes” porque eles são mais fáceis de } \\
\text { descartar }\end{array}$ & 6,6 & 2,8 \\
\hline MÉDIA GERAL & 6,3 & \\
\hline
\end{tabular}

Fonte: dados da pesquisa. 
Apesar das médias abaixo de seis pontos para a satisfação, valor percebido, qualidade percebida - entre outros itens - das marcas verdes, a preferência dos jovens consumidores por essas marcas apresenta um valor um pouco superior aos registrados pelas outras dimensóes (Tabela 7). Assim, apesar de uma avaliaçáo não tão positiva sobre as marcas verdes, os jovens consumidores possuem uma disposição um pouco maior em comprarem esse tipo de produto. Ressalta-se que as médias entre os itens desse construto variaram muito pouco entre si, assim como os valores do desvio padrão (apesar do maior valor para a última questão).

A percepção da preferência pelas marcas verdes é um construto que deve ser medido, pois, pode indicas a tendência dos consumidores em adquirir ou consumir produtos e serviços de marcas verdes no futuro (MOURAD; AHMED, 2012; IRFAN et al., 2014).

Tabela 8 - Percepção da lealdade

\begin{tabular}{l|c|c}
\hline \multicolumn{1}{c|}{ Questão } & Média & $\begin{array}{c}\text { Desvio } \\
\text { Padrão }\end{array}$ \\
\hline $\begin{array}{l}\text { Eu sempre vou usar marcas “verdes” por causa de sua preocupação com o } \\
\text { meio ambiente. }\end{array}$ & 5,8 & 2,8 \\
\hline $\begin{array}{l}\text { Eu irei comprar marcas “verdes” em um futuro próximo, porque são } \\
\text { marcas ambientalmente amigáveis. }\end{array}$ & 6,2 & 2,8 \\
\hline $\begin{array}{l}\text { As marcas “verdes” são sempre a minha primeira opção em relação às } \\
\text { marcas convencionais }\end{array}$ & 4,7 & 2,8 \\
\hline MÉDIA GERAL & 5,6 & \\
\hline
\end{tabular}

Fonte: dados da pesquisa.

A partir dos resultados exibidos na Tabela 8 , percebe-se que a lealdade em relação às marcas verdes, obteve uma média baixa, sendo possível concluir que os jovens consumidores não são leais às marcas "verdes". Esse resultado é coerente com a percepção já descrita para itens como a qualidade percebida, o valor percebido, a satisfação e afins. As marcas verdes nem sempre serão a primeira opção de compra e por isso a média geral da Lealdade foi baixa. Em relação ao desvio padrão, os valores apesar de altos foram idênticos entre as três questôes sobre a percepção de lealdade, indicando o mesmo nível de divergência para todas as questôes.

A lealdade é um dos construtos centrais no marketing, podendo ser considerado um dos objetivos principais das organizaçōes, haja vista todas as vantagens em ter consumidores leais à marca (MARTÍNEZ). Além disso, a lealdade à marca também afeta a força da marca percebida pelos consumidores (KANG; HUR, 2012). 


\begin{tabular}{l|c|c}
\hline \multicolumn{1}{c|}{ Questáo } & Média & $\begin{array}{c}\text { Desvio } \\
\text { Padráo }\end{array}$ \\
\hline $\begin{array}{l}\text { Faz sentido comprar marcas “verdes", em vez de outras marcas } \\
\text { convencionais, por causa dos compromissos ambientais das marcas } \\
\text { "verdes”, mesmo que os produtos sejam muito parecidos. }\end{array}$ & 6,0 & 2,4 \\
\hline $\begin{array}{l}\text { Mesmo que as marcas convencionais tenham as mesmas características } \\
\text { ambientais das marcas “verdes", eu prefiro comprar as marcas “verdes". }\end{array}$ & 5,6 & 2,5 \\
\hline $\begin{array}{l}\text { Mesmo que os produtos tenham as mesmas funcionalidades e } \\
\text { desempenho, eu prefiro comprar produtos de marcas “verdes". }\end{array}$ & 5,7 & 2,5 \\
\hline $\begin{array}{l}\text { Parece mais inteligente para mim, comprar produtos de marcas "verdes" } \\
\text { do que produtos de marcas convencionais, mesmo que os produtos sejam } \\
\text { idênticos. }\end{array}$ & 6,0 & 2,5 \\
\hline MÉDIA GERAL & 5,8 & \\
\hline
\end{tabular}

Fonte: dados da pesquisa.

Em consonância com as outras avaliações já descritas sobre a marca verde, a sua força em relação ao jovem consumidor é baixa (Tabela 9). As questóes que formam esse construto apresentaram pouca variação entre si, sendo que a maior delas abaixo de $10 \%$ entre as questóes. Em suma, a força das marcas verdes entre os jovens consumidores é baixa. Da mesma forma que ocorreu com alguns itens anteriores, os valores do desvio padrão são altos e possuem valores muito próximos entre si, indicando um mesmo nível de divergência entre as questóes.

Da mesma forma que ocorre com a lealdade à marca, a força da marca é um construto muito importante tanto para os gestores de marketing, quanto para os pesquisadores. A força da marca é importante, pois, gera muitas vantagens competitivas para as empresas (CHEN, 2010; KANG; HUR, 2012; NG et al., 2013; CHANG; CHEN, 2014)

Tabela 10 - Percepção do risco

\begin{tabular}{l|c|c}
\hline \multicolumn{1}{c|}{ Questão } & Média & $\begin{array}{c}\text { Desvio } \\
\text { Padráo }\end{array}$ \\
\hline $\begin{array}{l}\text { Existe a possibilidade dos produtos de marcas verdes não terem um bom } \\
\text { desempenho "ambiental". }\end{array}$ & 5,4 & 3,0 \\
\hline $\begin{array}{l}\text { Há uma boa chance de que os produtos de marcas verdes não funcionarão } \\
\text { corretamente no que diz respeito às funcionalidades ambientais. }\end{array}$ & 5,1 & 3,1 \\
\hline $\begin{array}{l}\text { Há uma boa chance de você causar problemas ambientais, se você usa os } \\
\text { produtos de marcas "verdes". }\end{array}$ & 4,0 & 3,0 \\
\hline $\begin{array}{l}\text { Há uma boa chance de que a utilizaçáo de produtos de marcas "verdes" } \\
\text { poderá afetar negativamente o meio ambiente. }\end{array}$ & 3,8 & 3,0 \\
\hline $\begin{array}{l}\text { Usar produtos de marcas “verdes" podem prejudicar a minha reputação de } \\
\text { pessoa preocupada com o meio ambiente. }\end{array}$ & 3,3 & 3,2 \\
\hline MÉDIA GERAL & 4,3 & \\
\hline
\end{tabular}

Fonte: dados da pesquisa. 
Os resultados alcançados em relação ao risco percebido por parte dos jovens consumidores (Tabela 10) indicam que ele pode ser avaliado como baixo, apresentando uma média um pouco acima dos quatro pontos. As questôes relacionadas com a percepção de outras pessoas e a consequência do uso de marcas verdes para o meio ambiente apresentaram a avaliação mais baixa por parte dos respondentes. Essa avaliaçáo de risco indica que o risco percebido sobre o uso de marcas verdes é baixo. Todavia, os altos valores para o desvio padrão indicam que existe uma grande divergência em relação a esse tópico. Apesar das médias baixas, muitos respondentes consideram que o risco percebido é alto.

Deve-se ressaltar ainda que a percepção de risco é um construto que afeta negativamente tanto a força da marca (CHANG; CHEN, 2014) quanto à intenção de compra da marca (RIZWAN et al., 2014).

Tabela 11 - Percepção do afeto

\begin{tabular}{l|c|c}
\hline \multicolumn{1}{c|}{ Questão } & Média & $\begin{array}{c}\text { Desvio } \\
\text { Padráo }\end{array}$ \\
\hline $\begin{array}{l}\text { Eu me sinto bem quando eu uso marcas que possuem preocupação am- } \\
\text { biental }\end{array}$ & 7,3 & 2,8 \\
\hline Em me sinto feliz ao comprar uma marca que cuida do meio ambiente. & 7,6 & 2,6 \\
\hline A marca que cuida do meio ambiente é prazerosa para mim & 7,7 & 2,6 \\
\hline MÉDIA GERAL & 7,5 & \\
\hline
\end{tabular}

Fonte: dados da pesquisa.

Em relação às questóes emocionais relacionadas ao uso de marcas verdes, a avaliação dos jovens consumidores é mais positiva do que foi observados para os outros construtos (Tabela 11). A avaliação de cada uma das questôes desse construto indica uma grande coerência entre si. No caso do desvio padrão, os resultados também são bastante similares entre os três itens. Em relação ao afeto para as marcas verdes, pode se considerar que os jovens consumidores possuem sentimentos e sensaçôes positivas em relaçáo ao seu uso.

A percepção de afeto dos consumidores em relação às marcas verdes de ser medido em virtude de que ele afeta positivamente a lealdade dos consumidores em relação às marcas verdes (KANG; HUR, 2012).

Tabela 12 - Percepção da preocupação ambiental

\begin{tabular}{l|c|c}
\hline \multicolumn{1}{c|}{ Questáo } & Média & $\begin{array}{c}\text { Desvio } \\
\text { Padrão }\end{array}$ \\
\hline Estou preocupado com a proteção do meio ambiente & 7,9 & 2,4 \\
\hline Eu me descreveria como ambientalmente responsável. & 5,6 & 2,8 \\
\hline A degradação ambiental tem aumentado nos últimos dez anos & 8,6 & 2,0 \\
\hline $\begin{array}{l}\text { A proteção do meio ambiente vai ajudar as pessoas a ter uma melhor quali- } \\
\text { dade de vida. }\end{array}$ & 8,5 & 2,2 \\
\hline
\end{tabular}




\begin{tabular}{l|c|c}
\hline \multicolumn{1}{c|}{ Questão } & Média & $\begin{array}{c}\text { Desvio } \\
\text { Padrão }\end{array}$ \\
\hline $\begin{array}{l}\text { Eu prefiro produtos de marcas “verdes” porque eles são mais fáceis de descar- } \\
\text { tar }\end{array}$ & 6,7 & 2,8 \\
\hline $\begin{array}{l}\text { Organizaçóes que promovem produtos verdes estão preocupadas com o } \\
\text { meio ambiente. }\end{array}$ & 6,9 & 2,5 \\
\hline MÉDIA GERAL & 7,4 & \\
\hline
\end{tabular}

Fonte: dados da pesquisa.

Em conjunto com o afeto, a preocupação ambiental (Tabela 12) é a variável que apresenta a segunda maior média entre os construtos. Esse valor poderia ser mais alto em virtude de que os jovens consumidores não se consideram ambientalmente responsáveis. Esse resultado é muito interessante, pois, indica uma oportunidade tanto para os gestores das empresas privadas, quanto para os gestores públicos, aumentarem o nível de preocupação ambiental dos jovens consumidores. É necessário ressaltar ainda que ela influencia positivamente a preferência dos consumidores pelas marcas verdes (IRFAN et al., 2014).

A percepção da preocupação ambiental apresentou alguns dos menores valores para o desvio padráo. Esse deve ser o item que apresentou a maior concordância entre os respondentes, tornando os valores obtidos nas médias ainda mais representativos.

Tabela 13 - Percepção da comunicação boca a boca

\begin{tabular}{l|c|c}
\hline \multicolumn{1}{c|}{ Questáo } & Média & $\begin{array}{c}\text { Desvio } \\
\text { Padráo }\end{array}$ \\
\hline $\begin{array}{l}\text { Eu encorajo meus amigos e parentes para comprar produtos com "marcas } \\
\text { verdes". }\end{array}$ & 4,6 & 2,6 \\
\hline $\begin{array}{l}\text { Se alguém está à procura de algum produto, eu geralmente aconselho a } \\
\text { comprar produtos com marcas "verdes". }\end{array}$ & 4,5 & 2,7 \\
\hline Eu digo coisas positivas sobre produtos com marcas “verdes" & 4,8 & 2,9 \\
\hline MÉDIA GERAL & 4,6 & \\
\hline
\end{tabular}

Fonte: dados da pesquisa.

A Tabela 13 apresenta os resultados relativos à comunicação boca a boca, os quais indicam uma média baixa, assim como suas perguntas constituintes. Assim, verifica-se que os jovens consumidores não procuram indicar ou influenciar os seus familiares e amigos acerca da utilização da marca verde. Esse resultado é coerente com os valores obtidos para a satisfação, qualidade percebida, valor percebido, autopercepção de responsabilidade ambiental, de além de outros itens relativos à avaliação das marcas verdes. Em relação ao desvio padrão, os resultados indicam que existem divergências entre os respondentes para cada um dos itens. Por fim, a comunicação boca a boca é um construto importante em virtude de que ela gera muitas vantagens para as marcas, principalmente quando o consumidor enxerga risco na compra e pede indicaçáo para outros consumidores (KONUK; RAHMAN; SALO, 2015) 
Tabela 14 - Percepção da propensão a pagar mais caro

\begin{tabular}{l|c|c}
\hline \multicolumn{1}{c|}{ Questáo } & Média & $\begin{array}{c}\text { Desvio } \\
\text { Padráo }\end{array}$ \\
\hline Estou disposto a gastar mais para comprar produtos de marcas “verdes”. & 3,1 & 3,0 \\
\hline $\begin{array}{l}\text { É aceitável a pagar um preço maior para comprar produtos de marcas } \\
\text { "verdes” por causa do seu desempenho ambiental. }\end{array}$ & 3,2 & 3,1 \\
\hline $\begin{array}{l}\text { Eu estou disposto a pagar mais caro para comprar produtos de marcas } \\
\text { "verdes" por causa de suas características ambientais. }\end{array}$ & 3,1 & 3,0 \\
\hline MÉDIA GERAL & 3,1 & \\
\hline
\end{tabular}

Fonte: dados da pesquisa.

O último construto analisado é a propensão em pagar mais caro, o qual apresentou o menor valor entre todos os outros analisados (Tabela 14). Verifica-se que os jovens consumidores não estão dispostos a pagar mais caro por produtos e serviços de marcas verdes. Contudo, se ressalta os altos valores para o desvio padrão. Assim, verifica-se que existe um grupo de consumidores que aceita pagar mais caro pelos produtos verdes. Da mesma forma que ocorreu com o construto anterior, Konuk, Rahman e Salo (2015) ressaltam a importância desse construto por causa da sua influencia na lucratividade das marcas verdes.

O próximo passo da análise foi analisar todos os construtos em conjunto. A Figura 1 apresenta um resumo das médias obtidas para todos os construtos.

Gráfico 1 - Avaliação média dos construtos em relação às marcas verdes

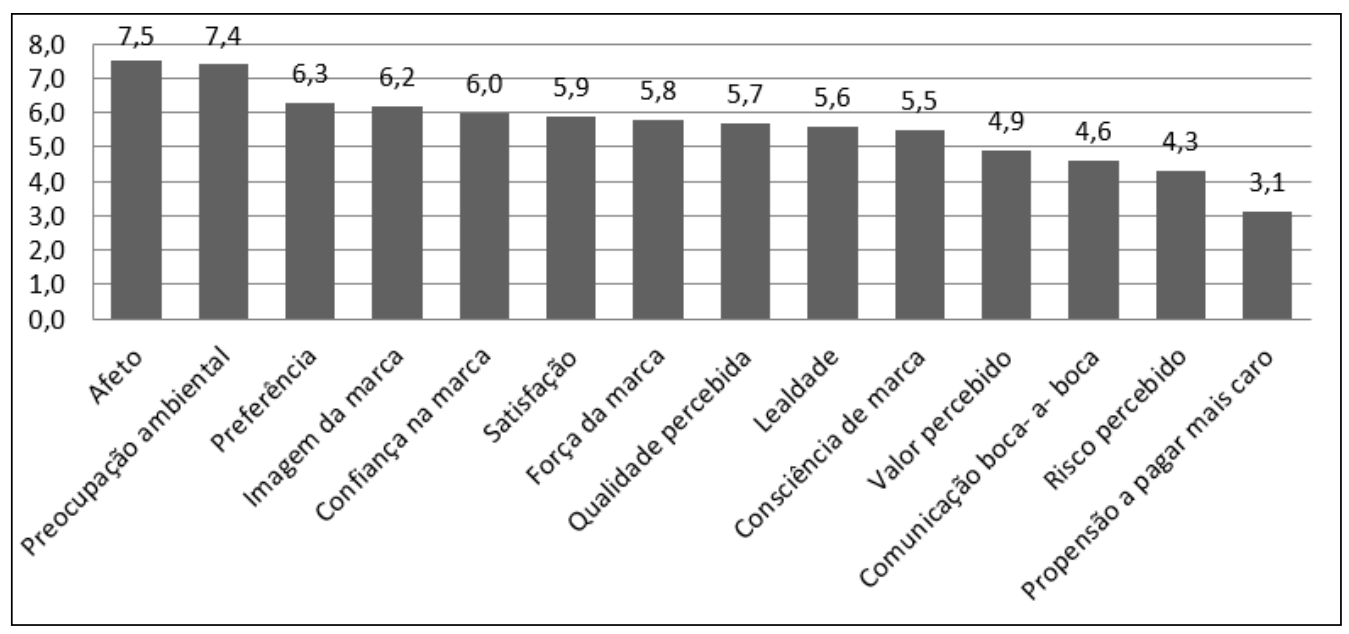

Fonte: dados da pesquisa.

Por meio das análises das médias dos construtos, sabe-se que os fatores que têm uma maior concordância em relação às marcas verdes são o afeto e a preocupação ambiental. Eles são responsáveis por mais de $70 \%$ de concordância em relação às marcas verdes. 
Portanto este primeiro grupo é formado por dois fatores que têm alto poder de influenciar os consumidores em seu processo de decisão de compra.

A preferência, a imagem da marca e a confiança na marca formam o segundo grupo de fatores. Eles são responsáveis por aproximadamente $60 \%$ de concordância dos jovens consumidores em relação às marcas verdes e podem influenciar positivamente o processo de escolha desses consumidores.

O terceiro grupo é formado pela satisfaçáo, pela força da marca, pela qualidade percebida, pela lealdade e pela consciência da marca. É o grupo que apresenta o maior número de construtos e possuem um nível de concordância acima de $50 \%$ e abaixo de $60 \%$.

Já o valor percebido, a comunicação boca a boca e o risco percebido formam o quarto grupo que apresentam valores acima de $40 \%$ e abaixo de $50 \%$. A sua influência em relaçáo ao comportamento de compra dos jovens consumidores em relação às marcas verdes é limitado.

O último grupo é formado pela propensão em pagar mais caro. Esse fator é de baixa influência na decisão de compra e os consumidores não estão dispostos a pagar mais caro por produtos que estejam em conformidade de marcas verdes. A influência exercida por ele é de apenas $31 \%$, sendo um obstáculo à disseminação desses produtos no mercado.

\section{CONSIDERAÇÓES FINAIS}

Os resultados obtidos nessa pesquisa, mostram que os jovens consumidores ainda não percebem um valor mercadológico como consumidores em termos das marcas verdes ou do green brand. Os construtos valor percebido, percepção de marca e atitudes e intençōes comportamentais desses consumidores em relação às marcas verdes é baixo para a grande maioria dos conceitos medidos na pesquisa.

Em relação às contribuiçóes teóricas desse trabalho pode-se destacar que não existem trabalhos no Brasil sobre marcas verdes ou green brand - a partir de pesquisas no banco de teses e dissertaçôes da CAPES (Coordenação de Aperfeiçoamento de Pessoal de Nível Superior), Scielo (Scientific Electronic Library Online) e Google Scholar. Assim, existe um avanço no conhecimento acerca da percepção dos jovens consumidores de marcas verdes no Brasil. Além disso, ao contrário do que foi encontrado em outros estudos já citados no referencial teórico, alguns resultados não são condizentes com o conhecimento existente sobre esse assunto, notadamente em termos da baixa percepção da importância das marcas verdes por parte dos jovens consumidores, bem como o baixo nível de fidelização e de intenção de pagar um preço premium por produtos e serviços de marcas verdes. No estudo de Fallah e Ebrahimi (2014) a consciência ambiental dos respondentes no Irã é alta e afeta fortemente a intenção de compra de produtos verdes e também pode influenciar a satisfação dos clientes como no estudo de Supriadi, Astuti e Firdiansyah (2017) realizado na Malásia. De outro lado, os resultados encontrados por Dieterich (2014) são condizentes com os resultados desse artigo e diferentes dos resultados citados acima. Apesar de uma percepção de consciência ambiental mediana por parte dos alemães, a tendência em comprar carros elétricos é bem baixa. 
As implicações gerenciais desse trabalho são muitas. Primeiramente é preciso ressaltar que os jovens consumidores não estáo dispostos a pagar um preço premium por produtos de marcas verdes, mesmo que eles tenham a preocupaçáo ambiental. Essa informaçáo é importante para a formação de preços e preparação de planos de negócios e planos de marketing para novos produtos ecologicamente sustentáveis. Em termos de comunicação de marketing a ênfase nessas características provavelmente não irá gerar resultados muito positivos, haja vista que os jovens consumidores percebem a qualidade desses produtos e a confiança em suas marcas somente de forma mediana, pois as avaliaçóes foram de 5,7 pontos e 6 pontos respectivamente.

De outro lado, o afeto apresentou a melhor avaliaçáo por parte dos respondentes. Essa é uma informação importante, pois, deve ser considerada em relação ao conteúdo e outros elementos da comunicaçáo de marca, bem como em termos de embalagens e locais de venda. Os aspectos emocionais e emotivos devem ser trabalhados de forma mais adequada, pois, apresentam uma maior influência na formação das crenças e percepçóes desses jovens consumidores. Além disso, o risco percebido por esses consumidores em relação às marcas verdes é baixo, provavelmente influenciado pela questão do afeto. Nesse caso, a possibilidade de experimentaçáo por parte dos consumidores é uma alternativa interessante para a penetração de novos produtos e serviços no mercado. Nesse processo, os jovens consumidores poderão perceber mais facilmente as vantagens desses novos produtos e serviços, bem como alterar as suas crenças e percepçóes acerca dos mesmos.

Ressalta-se ainda que os consumidores consideram que as marcas verdes são mais caras do que os produtos comuns e, nesse caso, a relação custo-benefício não é adequada. Assim, esse processo de experimentação também pode influenciar os jovens consumidores.

No caso das limitaçóes dessa pesquisa, a principal limitação ocorre em virtude da impossibilidade de generalização de resultados, haja vista que a amostra não é representativa da populaçáa jovem existente no Brasil. A amostra foi formada por estudantes de uma IES e a coleta de dados ocorreu em duas cidades. Assim, a percepçáo sobre as marcas verdes pode ser diferente em relaçáo a outros jovens estudantes brasileiros, bem como também em relaçáo aqueles que não estấo fazendo um curso superior.

Em relação aos estudos futuros as possibilidades são diversas. Primeiramente podese realizar a mesma pesquisa com uma amostra mais representativa. Verifica-se também que as características demográficas podem influenciar a percepção dos jovens consumidores (o gênero, a renda, local aonde vive e etc.). Além disso, técnicas estatísticas multivariadas podem ser usadas para verificar em termos significativos a relação entre os diversos construtos tanto a intençáo de compra quanto também o comportamento de compra desses jovens consumidores.

\section{REFERÊNCIAS}

AAKER, D. A. Measuring brand equity across products and markets. California management review, v. 38, n. 3, p. 102-120, 1996. 
BONINI, S.; Oppenheim, J. Cultivating the green consumer. Stanford Social Innovation Review, v. 6, n. 4, p. 56-61, 2008.

CASTRO, B. R. V.; MOURA, L. R. C.; CUNHA, N. R. da S.; PIRES, R. R. O marketing verde na tecnologia da informação: Percepçôes das atitudes e comportamentos dos profissionais de TI e açóes para incrementar o marketing verde nesse setor. Revista de Gestáo Ambiental e Sustentabilidade, v. 5, n. 1, p. 45-60, 2016.

CHANG, C. H.; CHEN, Y. S. Managing green brand equity: the perspective of perceived risk theory. Quality \& Quantity, v. 48, n. 3, p. 1753-1768, 2014.

CHEN, Y. S. The drivers of green brand equity: Green brand image, green satisfaction, and green trust. Journal of Business ethics, v. 93, n. 2, p. 307-319, 2010.

CHEN, Y. S. Green organizational identity: sources and consequence. Management Decision, v. 49, n. 3, p. 384-404, 2011.

CHEN, Y. S.; LAI, S. B.; WEN, C. T. The influence of green innovation performance on corporate advantage in Taiwan. Journal of business ethics, v. 67, n. 4, p. 331-339, 2006.

\section{DIETERICH, J. A Quantitative Analysis of Consumer Behaviour in Relation to} Electronic Cars Resulting in a New Green Marketing Approach For The German Car Industry. 2014, 88p. Dissertação (Master Business Administration) - MBA Programme, Dublin Business School. Dublin.

DOSZHANOV, A.; AHMAD, Z.A. Customers' intention to use green products: The impact of green brand dimensions and green perceived value. XVIII SHS Web of Conferences. EDP Sciences, 2015.

FALLAHA, M.; EBRAHIMI, M. R. A Study on the Effect of Green Marketing on Consumers' Purchasing Intention. Management Science Letters, v. 4, n. 3, p. 421-424, 2014.

FARQUHAR, P. H. Managing brand equity. Marketing research, v. 1, n. 3, p. 24-33, 1989.

GREGG, D. G.; WALCZAK, S. Dressing your online auction business for success: An experiment comparing two eBay businesses. Mis Quarterly, v. 32, n. 3, p. 653-670, 2008.

IRFAN, M.; SABIR, R. I.; LODHI, R. N.; MUKHTAR, A. Towards green brand preferences: impact of green practices on buying habits in Pakistan's food sector. Social and Basics Sciences Research Review, v. 1, n. 2, p. 85-96, 2014. 
JANG, Y. J.; KIM, W. G.; LEE, H. Y. Coffee shop consumers' emotional attachment and loyalty to green stores: The moderating role of green consciousness. International Journal of Hospitality Management, v. 44, n. 1, p. 146-156, 2015.

KANG, S.; HUR, W. M. Investigating the antecedents of green brand equity: a sustainable development perspective. Corporate Social Responsibility and Environmental Management, v. 19, n. 5, p. 306-316, 2012.

KAUR, S. Impact of Green Marketing on Consumer's Buying Behavior. Abhinav National Monthly Refereed Journal of Research In Commerce \& Management. v. 3, n. 5, p.1-8, May, 2014.

KONUK, F. A., RAHMAN, S. U.; SALO, J. Antecedents of green behavioral intentions: a cross-country study of Turkey, Finland and Pakistan. International Journal of Consumer Studies, v. 39, n. 6, p. 586-596, 2015.

MARTÍNEZ, P. Customer loyalty: exploring its antecedents from a green marketing perspective. International Journal of Contemporary Hospitality Management, v. 27, n. 5 , p. $896-917,2015$.

MOURAD, M.; AHMED, S. E. A. Perception of green brand in an emerging innovative market. European Journal of Innovation Management, v. 15, n. 4, p. 514-537, 2012.

NG, P. F.; BUTT, M. M.; KHONG, K. W.; ONG, F. S. Antecedents of green brand equity: an integrated approach. Journal of Business Ethics, v. 121, n. 2, p. 203-215, 2014.

OTTMAN, J. Marketing Verde: desafios e oportunidades para a nova era do marketing. São Paulo: Makron Books, 1994.

PEATTIE, K. Trappings versus substance in the greening of marketing planning. Journal of Strategic Marketing, v. 7, n. 2, p. 131-148, 1999.

POLONSKY, M. J. Green marketing regulation in the US and Australia: the Australian checklist. Greener Management International, v. 5, n. 1, p. 44-53, 1994.

RASIDAH, H.; JAMAL, S. A.; SUMARJAN, N. A Conceptual Study of Perceived Value and Behavioral Intentions in Green Hotels. Australian Journal of Basic and Applied Sciences. v. 8, n. 5, p. 254-259, 2014.

RIZWAN, M.; KHAN, A. A.; MISBAH, K. A.; NAWAZ, I.; TAHIR, S.; SIDDIQUE, A.; GILLANI, S. N. A. Measuring the scope of green products in developing countries: a myth breaking study. American Journal of Scientific Research, v. 5, n. 85, p. 32-46, 2011. 
RIZWAN, M.; MAHMOOD, U.; SIDDIQUI, H.; TAHIR, A. An empirical study about green purchase intentions. Journal of Sociological Research, v. 5, n. 11, p. 290-305, 2014.

SUPRIADI, B.; ASTUTI, W.; FIRDIANSYAH, A. Green Product And Its Impact on Customer Satisfaction. Journal of Business and Management, v. 19, n. 8, p. 35-42, 2017.

TRUJILLO, A.; ARROYO, P.; CARRETE, L. Do environmental practices of enterprises constitute an authentic green marketing strategy? A case study from Mexico. International Journal of Business and Management, v. 9, n. 2, p. 175, 2014. 